Open Access

\title{
Progesterone elevation on the day of human chorionic gonadotropin administration adversely affects the outcome of IVF with transferred embryos at different developmental stages
}

Yan Huang, En-yin Wang, Qing-yun Du, Yu-jing Xiong, Xiao-yi Guo, Yi-ping Yu and Ying-pu Sun*

\begin{abstract}
Background: The effect of progesterone elevation (PE) on the day of human chorionic gonadotropin (hCG) administration on the pregnancy outcomes of in vitro fertilization/intracytoplasmic sperm injection (IVF/ICSI) cycles is a matter of ongoing debate. The replacement of cleavage-stage embryos with blastocyst-stage embryos for transfer was proposed to avoid the possible impairment of PE in fresh cycles. This study aimed to assess the association between PE on the day of human chorionic gonadotropin ( $\mathrm{hCG}$ ) administration and clinical pregnancy rates (CPRs) in IVF/ICSI cycles with embryos transferred at different developmental stages (cleavage and blastocyst). Moreover, a secondary aim was to determine the thresholds at which PE has a detrimental effect on CPRs.
\end{abstract}

Methods: This single-center retrospective cohort study included more than 10,000 patients undergoing day 3 cleavage-stage embryo transfer (ET) and 1146 patients undergoing day 5 blastocyst-stage embryo transfer (ET) using gonadotropin and $\mathrm{GnRH}$ agonist for controlled ovarian stimulation.

Results: Serum PE was inversely associated with CPRs in both cleavage- and blastocyst-stage ET cycles. In the day 3 ET cycles, CPRs (progesterone levels $<0.5 \mathrm{ng} / \mathrm{ml}, 49.2 \%$ ) significantly declined when the progesterone concentration reached $1.0 \mathrm{ng} / \mathrm{ml}(45.5 \%)$ and decreased further when the progesterone concentration increased to $1.5 \mathrm{ng} / \mathrm{ml}(36.2 \%)$. In the day 5 blastocyst-stage ET cycles, patients with serum progesterone levels $\geq 1.75 \mathrm{ng} / \mathrm{ml}$ had significantly lower CPRs (31.3\% VS. $41.4 \%, p<0.001)$ compared to patients with serum progesterone levels $<1.75 \mathrm{ng} / \mathrm{ml}$. The negative association of PE with CPRs was noted in both ET groups, even after adjusting for confounders. Furthermore, the developmental stage of the transferred embryos was not linked to the effect of PE on CPRs because the interaction between the developmental stage of the transferred embryos and PE was not significant.

Conclusions: PE on the day of hCG administration is associated with decreased CPRs in GnRH agonist IVF/ intracytoplasmic sperm injection (ICSI) cycles regardless of the developmental stage of the transferred embryos (cleavage versus blastocyst stage).

Keywords: IVF, Progesterone, Pregnancy rate, GnRH agonist, Blastocyst

\footnotetext{
*Correspondence: syp2008@vip.sina.com

Department of Reproductive Medical Center, First Affiliated Hospital of Zhengzhou University, Jianshe Dong Road, Erqi District, Zhengzhou City, Henan Province, People's Republic of China
} 


\section{Background}

Despite the widespread use of gonadotropin-releasing hormone $(\mathrm{GnRH})$ analogues for pituitary down-regulation, progesterone elevation (PE), which refers to an increase in serum progesterone concentrations, still occurs at different frequencies on the day of human chorionic gonadotropin (hCG) administration for final oocyte maturation in fresh in vitro fertilization (IVF) cycles [1]. Moreover, the question of whether PE on the day of hCG administration affects the outcomes of IVF is still being debated [2-12]. Some studies have indicated that PE does not affect the probability of pregnancy in IVF $[2-4,12]$; however, other studies have concluded that PE resulted in a decreased probability of pregnancy [5-11]. The use of simple bivariate analyses and arbitrary cut-off levels in most of these studies may explain these varying results. Recently, a large-sample meta-analysis confirmed the adverse effect of PE on IVF pregnancy outcomes [1].

The precise endocrinological mechanism underlying the adverse effects of PE is still unclear; however, oocyte quality [13] and endometrial receptivity [14, 15] may play roles in this process. The hypothesis regarding endometrial receptivity is seemingly more convincing because of the results of gene expression studies on the endometrium $[16,17]$ and studies showing that the live birth rates of women implanted with frozen-thawed embryos or donor oocytes from fresh cycles did not significantly differ between those with PE and those without PE $[1,18]$.

Several strategies have been proposed to avoid the possible detrimental effects of PE in fresh IVF cycles $[19,20]$. One strategy is to replace cleavage-stage embryos with blastocyst-stage embryos prior to transfer because evidence suggests that PE does not decrease pregnancy rates in day 5 single blastocyst transfer cycles $[7,21]$. However, the reliability of these results has not been confirmed, and some researchers have found that PE can still impair IVF outcomes, even in blastocyst transfers $[8,13,22]$.

Hence, the aim of this study was to assess the association between PE on the day of hCG administration and the clinical pregnancy rates (CPRs) of GnRH agonist IVF/intracytoplasmic sperm injection (ICSI) cycles with the transfer of embryos at different developmental stages. Moreover, a secondary aim was to determine the thresholds at which PE has a detrimental effect on CPRs.

\section{Material and methods}

\section{Study population}

This was a single-center retrospective cohort study. Patients who were undergoing IVF with gonadotropin and a GnRH agonist for controlled ovarian stimulation were enrolled from January 2010 to October 2014. A total of 10,864 patients were assigned to the day 3 embryo transfer (ET) group undergoing cleavage-stage ET, and 1146 patients were assigned to the day 5 ET group undergoing blastocyst-stage ET. The Ethics Committee of the First Hospital of Zhengzhou University approved the research protocol for this study.

The exclusion criteria were as follows: (i) individuals in the first or second oocyte or sperm donation cycles and (ii) couples in which either member had chromosomal abnormalities. Each patient was included in the study only once, during either the first or second IVF/ ICSI cycle.

The following patient characteristics were evaluated: age, basal follicle-stimulating hormone (bFSH) level, body mass index (BMI), cause of infertility, duration of infertility and type of infertility. Other measured parameters included the dose and type of gonadotropin; the duration of gonadotropin administration; serum endometrial thickness and P/E2/LH levels (on the hCG day); and the numbers of retrieved oocytes, two pronuclear (2PN) oocytes, 2PN cleavage embryos, available embryos and transferred embryos. All data were collected from computerized databases.

\section{Controlled ovarian stimulation and embryo transfer}

The selected protocols included a standard long GnRH agonist protocol and a prolonged or modified prolonged GnRH agonist protocol [23, 24]. Clinicians selected an appropriate protocol for each patient on a case-by-case basis based on patient characteristics.

Pituitary suppression was achieved by injecting triptorelin acetate (Decapeptyl ${ }^{\odot} 0.1 \mathrm{mg}$ [Ferring, Germany] or Diphereline $^{\oplus} 0.1 / 3.75 \mathrm{mg}$ [Ipsen, France]) until the serum levels of E2, follicle-stimulating hormone (FSH) and $\mathrm{LH}$ were $<30 \mathrm{mIU} / \mathrm{mL},<5 \mathrm{mIU} / \mathrm{mL}$ and $<5 \mathrm{mIU} /$ $\mathrm{mL}$, respectively. Controlled ovarian stimulation was initiated with several types of gonadotropin, with follicle stimulating hormone (FSH) activity (Gonal-F ${ }^{\oplus} 75$ IU [Serono, Switzerland], Fostiman 75 IU [IBSA, Switzerland], or Puregon 50 IU [N. V. Organon, Netherlands]) or with FSH combined with luteinizing hormone (LH) activity (hMG ${ }^{\oplus}$, Livzon, China). In general, the initial dose of gonadotropins, which ranged from 112.5 IU to $400 \mathrm{IU}$, was based on the individual's age, BMI, bFSH and response during previous stimulated cycles and the presence of polycystic ovary syndrome (PCOS).

After at least 4 days of stimulation, doses were adjusted based on the ovarian response, as evaluated using ultrasonography and serum E2 measurement. When more than three follicles reached $17 \mathrm{~mm}$, hCG was injected, and after 36-37 h, oocyte retrieval was performed.

A grading criterion was used to evaluate the quality of the cleavage-stage embryos [25]. Grade 1 and Grade 2 embryos with $\geq 6$ symmetrical blastomeres of equal size 
were considered top-quality embryos. Generally, patients with three or more top-quality cleavage-stage embryos were likely to be candidates for blastocyst culture. A scoring system developed by Gardner was applied for blastocyst-stage embryo grading [26]. A blastocyst with a grade $\geq 3 \mathrm{BB}$ was considered a top-quality embryo. According to national regulations, the number of embryos per patient, and other individual requirements, 1-3 of the best day 3 embryos or 1-2 of the best day 5 blastocysts were selected for transfer. In addition, when the progesterone level had increased to more than $2.5 \mathrm{ng} / \mathrm{ml}$ before hCG, all embryos were frozen and transferred in sequential frozen ET cycles.

\section{Serum hormone measurements}

Basal FSH was measured on days 2-4 of the menstrual cycle before the IVF cycle began. Hormones, including LH, E2 and P, were assessed during controlled ovarian stimulation (once every 2-4 days at first and once a day during the late follicular phase and on the day of hCG administration in each cycle). All blood samples were taken during fasting, generally between $6: 30$ and 7:30 am. We used an individual immunoanalyzer (Roche Cobas e411; Roche Diagnostics, Mannheim, Germany) and the same assays for all hormone measurements during the entire study.

Serum progesterone levels were measured using an electrochemiluminescence immunoassay with Progesterone II (Cobas 12145383). The assay's limit was $0.03 \mathrm{ng} /$ $\mathrm{ml}$, and its sensitivity was $0.15 \mathrm{ng} / \mathrm{ml}$. The intra-assay and inter-assay coefficients of variation were 3.0 and $5.5 \%$, respectively.

\section{Outcome variables}

The CPR was the primary outcome. The presence of an intrauterine gestational sac (with positive cardiac pulsations on ultrasound) at 35 or 45 days after ET was considered to indicate a clinical pregnancy. Other rates were also calculated: the implantation rate $(\mathrm{IR})=$ number of sacs (both within and outside the uterine cavity)/the number of transferred embryos; the fertilization rate $=$ the number of 2PN oocytes/the number of oocytes retrieved; and the cleavage rate $=$ the number of $2 \mathrm{PN}$ cleavage-stage embryos/the number of $2 \mathrm{PN}$ oocytes.

\section{Statistical analysis}

The continuous variables are described using means and standard deviations (SDs) or medians and interquartile ranges (IQRs). The categorical variables are described as percentages of the total. Student's $t$-test or the MannWhitney $U$ test were applied for single comparisons, and one-way analysis of variance (ANOVA) followed by the least significant difference (LSD) $t$ test or the KruskalWallis (KW) test followed by all pairwise multiple comparisons were used for multiple comparisons of the continuous variables based on the normality of the distribution. For categorical variables, the chi-square test or Fisher's exact test was performed.

Because the relationship between serum progesterone levels and pregnancy rates was assumed to be non-linear [19], the patients in the day 3 and day 5 ET groups were divided into the following eight distinct groups for analyses according to their serum progesterone levels on the day of hCG: <0.50, 0.50-074, 0.75-0.99, 1.00-1.24, 1.25$1.49,1.50-1.74,1.75-1.99$ and $\geq 2.00 \mathrm{ng} / \mathrm{ml}[5,6]$. To assess the association between PE and CPRs and determine the thresholds at which PE has a detrimental effect on CPRs, CPRs were calculated for each group and subjected to a Mantel-Haenszel test for trend analysis. Furthermore, the odds ratios (ORs) and $95 \%$ confidence intervals (CIs) of the CPRs were calculated to confirm the thresholds by comparing each group to the group with the lowest progesterone level $(<0.50 \mathrm{ng} / \mathrm{ml})$. Pairwise comparisons were also made between adjacent groups, as follows: $<0.50$ and $0.50-0.74 \mathrm{ng} / \mathrm{ml}, 0.50-0.74$ and $0.75-0.99 \mathrm{ng} / \mathrm{ml}, 0.75-0.99$ and $1.00-1.24 \mathrm{ng} / \mathrm{ml}, 1.00-1.24$ and $1.25-1.49 \mathrm{ng} / \mathrm{ml}, 1.25-$ 1.49 and $1.50-1.74 \mathrm{ng} / \mathrm{ml}, 1.50-1.74$ and $1.75-1.99 \mathrm{ng} / \mathrm{ml}$, and 1.75-1.99 and $\geq 2.00 \mathrm{ng} / \mathrm{ml}$. Moreover, the developmental stage of the transferred embryos (cleavage versus blastocyst stage), PE (defined as an unordered categorical variable according to progesterone levels: $<0.50,0.50-074$, $0.75-0.99,1.00-1.24,1.25-1.49,1.50-1.74,1.75-1.99$ and $\geq 2.00 \mathrm{ng} / \mathrm{ml}$ ) and the interaction terms between them were examined in multivariate logistic regression analyses and evaluated together with other confounders to assess the effect of the developmental stage of the transferred embryos on the association PE with CPR. The confounders included female age, BMI, gonadotropin dose, the number of retrieved oocytes, the number of transferred embryos, the number of top-quality transferred embryos, and serum E2 levels on the day of hCG administration $[27,28]$.

After appropriate progesterone threshold levels were determined for the day 3 and day 5 ET groups, the serum progesterone levels were subdivided based on the threshold and were subjected to multivariate logistic regression analyses while controlling for other confounders to more accurately determine the effect of serum PE on CPRs. Additionally, the patients in these two groups were classified into several subgroups according to each group's progesterone cut-off level. The demographic and clinical characteristics of the individuals in these subgroups were then compared.

\section{Results}

\section{Patient characteristics}

The included patients' baseline characteristics are shown in Table 1. A total of 10,864 patients underwent day 3 
ET, and a total of 1146 patients underwent day 5 ET in IVF/ICSI/IVF + ICSI cycles. The median (IQR) bFSH levels of these patients were $7.16(2.5)$ and $6.57(2.0)$ IU/L, respectively. A total of $84.3 \%$ patients in the day 3 ET group and $88.1 \%$ patients in the day 5 ET group were in their first IVF/ICSI cycles. Several relatively clear causes of infertility were present in the patients in the day 3 and day 5 ET groups, including tubal pathology (44.5 and $58.5 \%$, respectively), male factors (27.5 and $29.8 \%$, respectively), advanced age ( $\geq 35$ years, 11.1 and $14.6 \%$, respectively), PCOS (6.2 and $11.5 \%$, respectively), and endometriosis ( 3.5 and $3.3 \%$, respectively).

Table 2 presents the clinical, oocyte and embryo parameters from controlled ovarian stimulation to ET. The median (IQR) duration and dose of gonadotropin were 11.0 (2.0) days and 2100 (1275) IU, respectively, in the day 3 group and 11.0 (2.0) days and 1637.5 (787) IU, respectively, in the day 5 group. The mean $( \pm \mathrm{SD})$ level of serum progesterone, the E2 level on the day of hCG, and the median (IQR) number of retrieved oocytes were

Table 1 Patients' baseline characteristics

\begin{tabular}{|c|c|c|}
\hline Parameter & Day 3 ET & Day 5 ET \\
\hline & $(n=10,864)$ & $(n=1146)$ \\
\hline Age (years) & $31.3 \pm 5.1$ & $29.7 \pm 4.5$ \\
\hline BMI $\left(\mathrm{kg} / \mathrm{m}^{2}\right)$ & $22.0(3.0)$ & $22.0(4.5)$ \\
\hline bFSH (IU/L) & $7.16(2.5)$ & $6.57(2.0)$ \\
\hline Duration of infertility (years) & $3(4)$ & $3(3)$ \\
\hline Primary infertility (\%) & 49.2 & 55.2 \\
\hline Second infertility (\%) & 50.8 & 44.8 \\
\hline First treatment cycle (\%) & 84.3 & 88.1 \\
\hline \multicolumn{3}{|l|}{ Cause of infertility (\%) } \\
\hline tubal pathology & 44.5 & 58.5 \\
\hline male factors & 27.5 & 29.8 \\
\hline advanced age ( $\geq 35$ years) & 11.1 & 14.6 \\
\hline PCOS & 6.2 & 11.5 \\
\hline endometriosis & 3.5 & 3.3 \\
\hline pelvic pathology & 6.5 & 6.5 \\
\hline others & 3.8 & 4.1 \\
\hline unexplained factors & 13.3 & 11.2 \\
\hline \multicolumn{3}{|l|}{ ART (\%) } \\
\hline IVF & 69.8 & 72.2 \\
\hline$|C S|$ & 28.8 & 25.6 \\
\hline$|\mathrm{IVF}+| \mathrm{ICSI}$ & 1.4 & 2.2 \\
\hline \multicolumn{3}{|l|}{ Stimulation protocol (\%) } \\
\hline GnRH-a long protocol & 82.8 & 93.5 \\
\hline GnRH-a prolonged (modified) protocol & 11.1 & 5.8 \\
\hline
\end{tabular}

Note: ART: assisted reproductive technology; IVF + ICSI: IVF + rescue ICSI or IVF + late ICSI; GnRH-a: gonadotropin-releasing hormone agonist; PCOS: polycystic ovary syndrome
Table 2 Clinical/oocyte/embryo parameters from ovarian stimulation to embryo transfer

\begin{tabular}{lll}
\hline Parameter & Day 3 ET & Day 5 ET \\
\hline & $(n=10,864)$ & $(n=1146)$ \\
Duration of stimulation (days) & $11.0(2.0)$ & $11.0(2.0)$ \\
Total dose of Gn (IU) & $2100(1275)$ & $1637.5(787)$ \\
Serum progesterone (ng/ml), hCG day & $0.83 \pm 0.44$ & $0.99 \pm 0.43$ \\
Serum E2 (pg/ml), hCG day & $4421.8 \pm 2570.0$ & $7696.2 \pm 2659.7$ \\
Serum LH (IU/L), hCG day & $1.88(1.13)$ & $1.46(0.87)$ \\
Endometrial thickness (mm), hCG day & $12.0(1.8)$ & $12.0(1.3)$ \\
Oocytes retrieved $(n)$ & $10(7)$ & $18(5)$ \\
2PN oocytes ( $n)$ & $6(5)$ & $14(4)$ \\
2PN cleavage embryos ( $n)$ & $6(5)$ & $13(4)$ \\
Available embryos $(n)$ & $5(4)$ & $9(4)$ \\
ET with a single embryo (\%) & 1.3 & 91.4 \\
ET with two embryos (\%) & 87 & 8.6 \\
ET with more than two embryos (\%) & 11.7 & $/$ \\
\hline
\end{tabular}

Note: Values are the mean \pm SD or median (IQR) unless otherwise noted; hCG: human chorionic gonadotropin; Gn: gonadotropin; E2: estrogen; LH: luteinizing hormone; ET: embryo transfer

$0.83 \pm 0.44 \mathrm{ng} / \mathrm{ml}, 4421.8 \pm 2570 \mathrm{pg} / \mathrm{ml}$ and 10 (7), respectively, in the day 3 group; these values were much higher in the day 5 group $(1.03 \pm 0.43 \mathrm{ng} / \mathrm{ml}, 7696.2 \pm$ $2659.7 \mathrm{pg} / \mathrm{ml}$ and 18 (5), respectively). Double ET occurred in most of the individuals in the day $3 \mathrm{ET}$ group (87\%), and single blastocyst-stage ET occurred in most of the individuals in the day 5 ET group (91.4\%).

\section{The relationship between serum progesterone levels and clinical pregnancy rates}

The relationships between serum progesterone levels on the day of hCG administration and CPRs in the day 3 ET group are shown in Fig. 1.

Serum progesterone levels were inversely related to CPRs in the day 3 ET group, as shown in Fig. 1a $(p<$ 0.0001 for overall trend). A decrease in CPRs was observed when the serum progesterone level was $\geq 1.0 \mathrm{ng} /$ $\mathrm{ml}$, and an additional reduction was observed when the serum progesterone level was $\geq 1.5 \mathrm{ng} / \mathrm{ml}$. By comparing each group to the group with the lowest progesterone level $(<0.5 \mathrm{ng} / \mathrm{ml})$, the ORs $(95 \% \mathrm{CIs})$ of CPRs were calculated (Fig. 1b). The CPRs of these five groups with progesterone levels $\geq 1.0 \mathrm{ng} / \mathrm{ml}$ were significantly lower than the CPRs of the group with the lowest progesterone level $(<0.5 \mathrm{ng} / \mathrm{ml})$. Furthermore, when the $0.75-0.99 \mathrm{ng} / \mathrm{ml}$ group was compared with the 1.00 $1.24 \mathrm{ng} / \mathrm{ml}$ group ( $49.8 \%$ VS. $45.5 \%, p=0.009$ ) and the $1.25-1.49 \mathrm{ng} / \mathrm{ml}$ group was compared with the 1.50 $1.74 \mathrm{ng} / \mathrm{ml}$ group ( $45.5 \%$ VS. $35.3 \%, p=0.002$ ), the differences were statistically significant. These data suggest that progesterone began to have a detrimental 

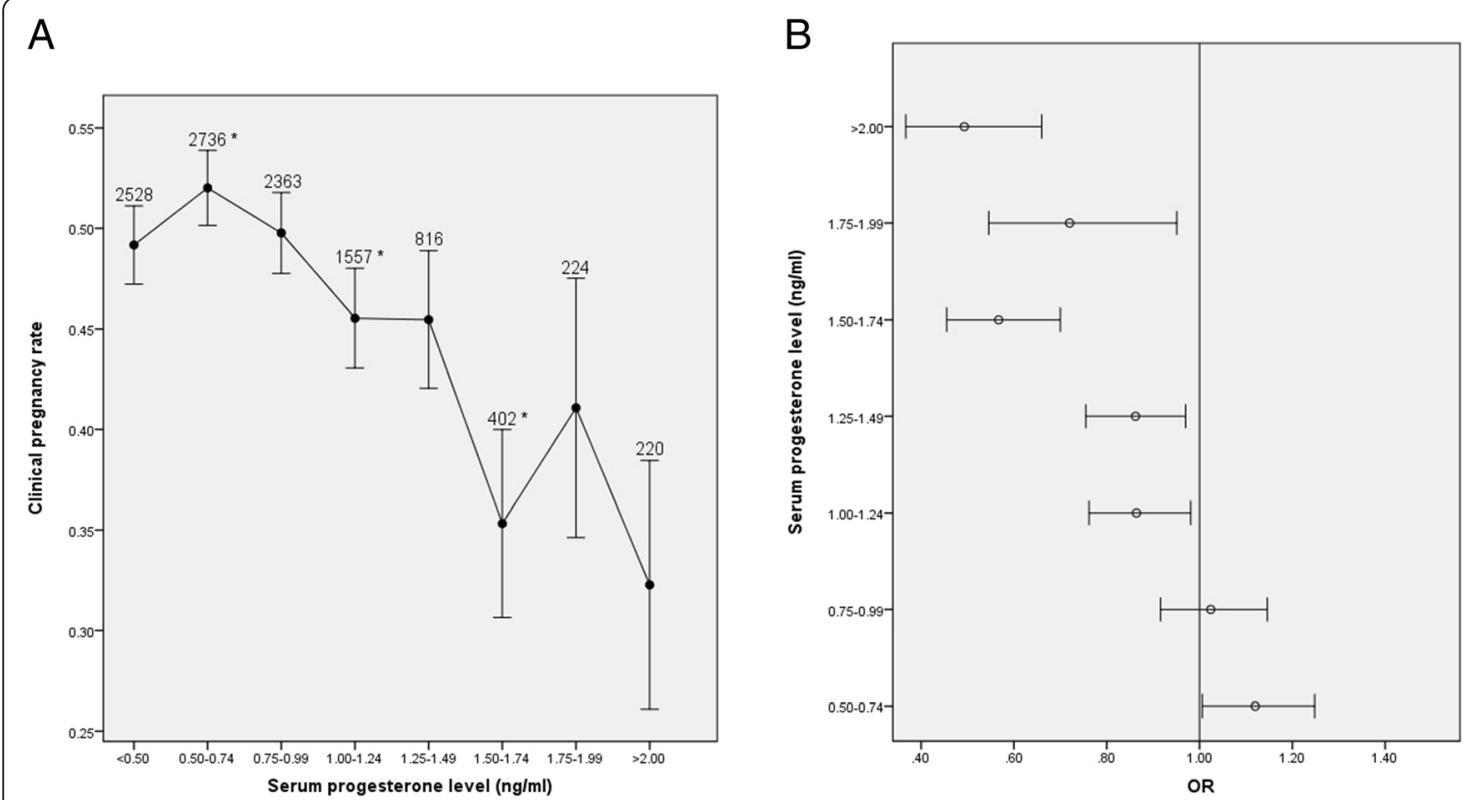

OR $(95 \% \mathrm{Cl})$

$0.493(0.367-0.660$

$0.720(0.546-0.951)$

$0.567(0.455-0.706)^{*}$

$0.862(0.755-0.970)$

$0.864(0.762-0.981)$ *

$1.024(0.916-1.146)$

$1.120(1.006-1.248)$

Fig. 1 Relationship between serum progesterone levels and CPRs in the day 3 ET group (a) Relationship between serum progesterone levels and CPRs, (b) CPRs according to serum progesterone levels. ${ }^{*} p<0.05$ for comparison with the previous progesterone group; data are expressed as the OR $(95 \% \mathrm{Cl})$ for each serum progesterone group compared with the group with the lowest progesterone level $(<0.5 \mathrm{ng} / \mathrm{ml})$; OR: odds ratio; $\mathrm{Cl}$ : confidence interval

effect on the probability of pregnancy in day 3 cleavage-stage ET cycles once the serum progesterone level reached $1.0 \mathrm{ng} / \mathrm{ml}$. When the progesterone concentration reached $1.5 \mathrm{ng} / \mathrm{ml}$, the detrimental effect appeared to worsen.
The relationships between serum progesterone levels and CPRs in the day 5 ET group are shown in Fig. 2.

The patients' serum progesterone levels were inversely associated with CPRs, as shown in Fig. 2a ( $p=0.0076$ for the overall trend). CPRs decreased with gradually higher
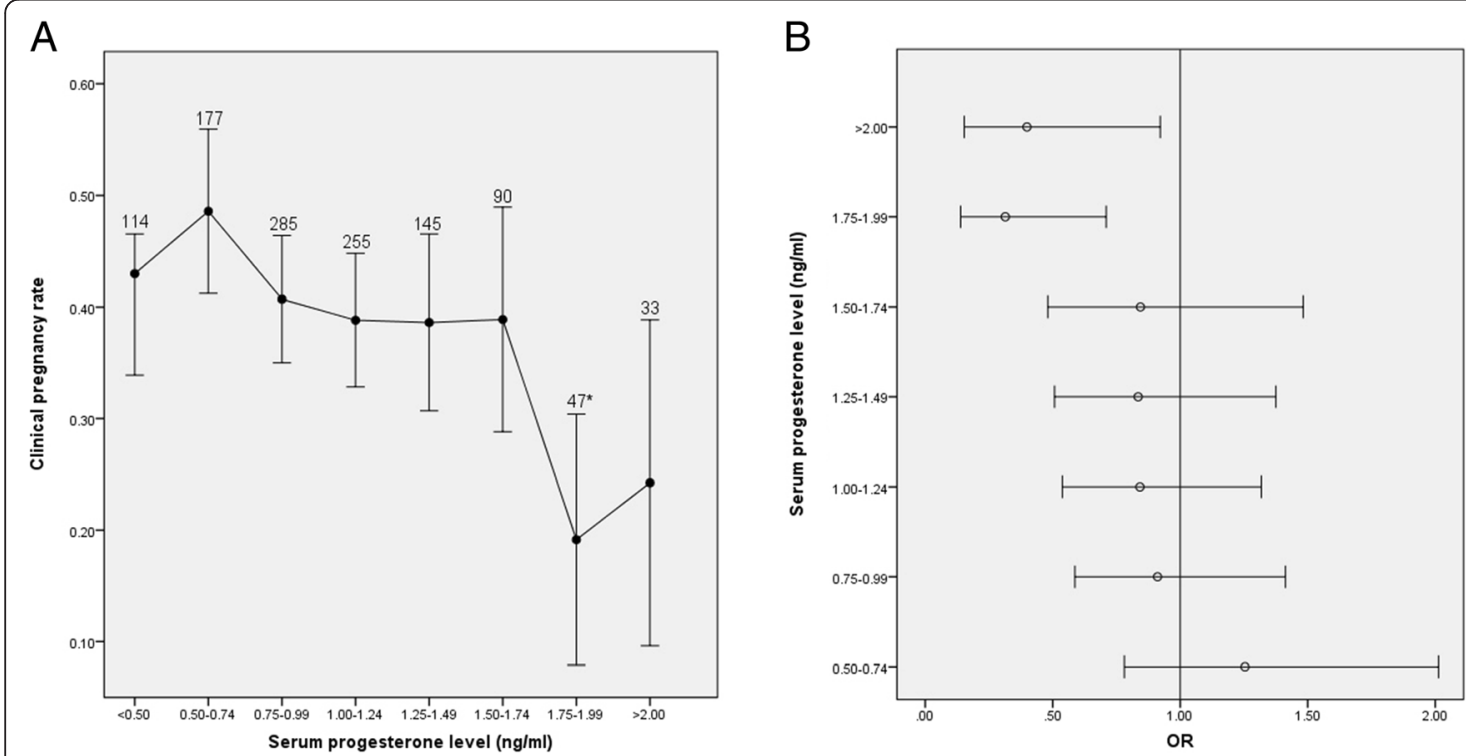

OR $(95 \% \mathrm{Cl})$

$1.254(0.781-2.013)$

$0.911(0.587-1.413)$ *

$0.842(0.538-1.318)$

$0.835(0.507-1.375)$

$0.844(0.481-1.482)$

$0.314(0.139-0.710)$

$0.399(0.153-1.922)$

Fig. 2 Relationship between serum progesterone levels and CPRs in the day 5 ET group (a) Relationship between serum progesterone levels and CPRs, (b) CPRs according to serum progesterone levels. ${ }^{*} p<0.05$ for comparison with the previous progesterone group; data are expressed as the OR ( $95 \% \mathrm{Cl}$ ) for each serum progesterone group compared with the group with the lowest progesterone level $(<0.5 \mathrm{ng} / \mathrm{ml})$; OR: odds ratio; Cl: confidence interval 
levels of serum progesterone, especially when the serum progesterone level was $\geq 1.75 \mathrm{ng} / \mathrm{ml}$. The ORs (95\% CI) of CPRs for each of the groups compared with the group with the lowest progesterone level $(<0.5 \mathrm{ng} / \mathrm{ml})$ are shown in Fig. 2b. Statistically significant reductions in CPRs were only observed in the 1.75-1.99 (OR: 0.307 [0.146-0.646], $p=0.001$ ) and $\geq 2 \mathrm{ng} / \mathrm{ml}$ groups (OR: 0.414 [0.184-0.934], $p=0.029$ ). Moreover, when adjacent groups were compared, the CPRs differed significantly only between the $1.5-1.74$ and $1.75-1.99 \mathrm{ng} / \mathrm{ml}$ groups ( $38.9 \%$ VS. $19.1 \%, p=0.019$ and $42.6 \%$ VS. $22.2 \%, p=$ 0.021 , respectively). These results imply that a serum progesterone concentration of $1.75 \mathrm{ng} / \mathrm{ml}$ was likely to be the cut-off level at which progesterone has an adverse impact on clinical pregnancy in IVF cycles with day 5 blastocyst-stage ETs.

\section{Multivariate analysis of factors associated with clinical pregnancy}

A multivariate logistic regression analysis showed that several factors were significantly associated with CPRs (Table 3). In the day 3 ET group, serum PE was negatively associated with CPRs (OR: 0.874 [0.823-0.929], $p$ $<0.001$ ), whereas the number of top-quality transferred embryos was positively associated with CPRs (OR: 1.073 [1.001-1.150], $p=0.047)$. The results were similar for the day 5 ET group ( $p<0.05$ for each comparison); however, female age was negatively associated with CPRs (OR: 0.770 [0.606-0.980], $p=0.03$ ).

\section{Interaction between the developmental stage of the transferred embryos and the effect of PE on CPRs}

To assess whether PE's effect on clinical pregnancy was influenced by the developmental stage of the transferred embryos, an interaction term of developmental stage of transferred embryos and PE was included in the multivariate analyses (Table 4). Female age, PE, the developmental stage of the transferred embryos and the number of transferred top-quality embryos were all significantly related to the CPR. However, the interaction term (developmental stage of transferred embryos" $\mathrm{PE}$ ) was not statistically significant $(p>0.05$ for all progesterone levels), which also could not support the possible influence of the transferred embryos on PE' effect on CPRs
Table 4 Interaction between the developmental stage of the transferred embryos and the effect of PE on CPRs

\begin{tabular}{lll}
\hline Factors & OR $(95 \% \mathrm{Cl})$ & $p$-value \\
\hline Female age (years) & $0.930(0.872-0.993)$ & 0.031 \\
No. of transferred TQE & $1.102(1.031-1.179)$ & 0.004 \\
Developmental stage & $0.842(0.718-0.987)$ & 0.004 \\
Progesterone elevation $(\mathrm{ng} / \mathrm{ml})^{\mathrm{a}}$ & & $<0.001$ \\
Developmental stage ${ }^{\mathrm{b}} \mathrm{PE}(\mathrm{ng} / \mathrm{ml})$ & & \\
$0-0.49$ & & 0.369 \\
$0.50-0.74$ & & 0.099 \\
$0.75-0.99$ & 0.921 \\
$1.00-1.24$ & & 0.828 \\
$1.25-1.49$ & 0.861 \\
$1.50-1.74$ & & 0.799 \\
$1.75-1.99$ & 0.058 \\
2- & & 0.228 \\
\hline
\end{tabular}

Note: TQE: top-quality embryo; OR: odds ratio; Cl: confidence interval. developmental stage: cleavage versus blastocyst stage, $\mathrm{PE}^{\mathrm{a}}$ was defined as an unordered categorical variable according to progesterone levels: $<0.50$, $0.50-074,0.75-0.99,1.00-1.24,1.25-1.49,1.50-1.74,1.75-1.99$ and $\geq 2.00 \mathrm{ng} / \mathrm{ml}$. The $95 \% \mathrm{Cls}$ of developmental stage ${ }^{\mathrm{b}} \mathrm{PE}$ were all covered 1

\section{Results of comparisons between subgroups}

Demographic and clinical characteristics were compared among the subgroups within the day 3 ET group (Table 5) and the day 5 ET group (Table 6).

In the day 3 ET group (Table 5), BMI and bFSH levels were lower in the $<1 \mathrm{ng} / \mathrm{ml}$ subgroup than in the $\geq 1.0 \mathrm{ng} /$ $\mathrm{ml}$ subgroups, whereas the dose of gonadotropin; the numbers of 2PN oocytes, cleavage-stage embryos and available embryos; and female age were higher. The serum LH levels, endometrial thickness on the day of hCG administration and cleavage rates were lower in the $\geq 1.5 \mathrm{ng} / \mathrm{ml}$ subgroup than in the $<1.5 \mathrm{ng} / \mathrm{ml}$ subgroups. When serum progesterone was elevated, the serum E2 levels and the number of retrieved oocytes were increased; however, fertilization rates, CPRs and IRs were significantly decreased.

In the day 5 ET group (Table 6), basal FSH levels, serum LH levels, fertilization rates and cleavage rates did not differ significantly between the two subgroups. The larger number of retrieved oocytes and higher serum E2 levels observed in the $\geq 1.75 \mathrm{ng} / \mathrm{ml}$ subgroup

Table 3 Multivariate analysis of factors related to clinical pregnancy

\begin{tabular}{lllll}
\hline Factors & Day 3 ET & & Day 5 ET \\
\hline & OR $(95 \% \mathrm{Cl})$ & $p$-value & OR $(95 \% \mathrm{Cl})$ & $p$-value \\
Female age(years) & $/$ & $/$ & $0.770(0.606-0.980)$ & 0.034 \\
PE', hCG day & $0.874(0.823-0.929)$ & $<0.001$ & $0.419(0.237-0.742)$ & 0.003 \\
No. of transferred TQEs & $1.073(1.001-1.150)$ & 0.047 & $1.331(1.045-1.696)$ & 0.021 \\
\hline
\end{tabular}

Note: TQE: top-quality embryo; athree levels of PE were defined in the day 3 ET group: $<1 \mathrm{ng} / \mathrm{ml}, 1-1.49 \mathrm{ng} / \mathrm{ml}$, and $\geq 1.5 \mathrm{ng} / \mathrm{ml}$; two levels of PE were defined in the day 5 ET group: $<1.75 \mathrm{ng} / \mathrm{ml}$ and $\geq 1.75 \mathrm{ng} / \mathrm{ml}$. OR: odds ratio; Cl: confidence interval 
Table 5 Comparisons of demographic and clinical characteristics between subgroups of the day 3 ET group

\begin{tabular}{|c|c|c|c|}
\hline \multirow[t]{2}{*}{ Parameter $^{a}$} & \multicolumn{3}{|c|}{ Serum P levels $(\mathrm{ng} / \mathrm{ml})$, day $3 \mathrm{ET}^{\mathrm{b}}$} \\
\hline & $<1.0$ & $1.0-1.49$ & $\geq 1.5$ \\
\hline No. of fresh cycles & 7627 & 2373 & 846 \\
\hline Female age (years) & $31.1 \pm 5.1$ & $31.8 \pm 5.0^{*}$ & $32.1 \pm 5.1$ \\
\hline BMI $\left(\mathrm{kg} / \mathrm{m}^{2}\right)$ & $22.7 \pm 3.2$ & $22.3 \pm 3.0^{*}$ & $22.1 \pm 3.0$ \\
\hline Basal FSH (IU/L) & $7.7 \pm 2.9$ & $7.3 \pm 2.4^{*}$ & $7.2 \pm 2.2$ \\
\hline Total dose of Gn (IU) & $2201.2 \pm 940.7$ & $2268.6 \pm 879.3^{*}$ & $2357.1 \pm 890.1^{*}$ \\
\hline Serum E2 (pg/ml), hCG day & $3941.8 \pm 2118.6$ & $5321.0 \pm 2353.8^{*}$ & $6201.8 \pm 4598.0^{*}$ \\
\hline Serum LH (IU/L), hCG day & $2.0 \pm 1.3$ & $1.9 \pm 1.4$ & $1.72 \pm 1.9^{*}$ \\
\hline Endometrial thickness (mm), hCG day & $12.3 \pm 2.4$ & $12.2 \pm 2.5$ & $12.0 \pm 2.4^{*}$ \\
\hline No. of oocytes retrieved & $9.3 \pm 4.4$ & $11.1 \pm 4.6^{*}$ & $12.0 \pm 4.8^{*}$ \\
\hline No. of 2PN oocytes & $6.4 \pm 3.3$ & $7.5 \pm 3.5^{*}$ & $7.8 \pm 4.8$ \\
\hline No. of 2PN cleavage embryos & $6.4 \pm 3.3$ & $7.5 \pm 3.5^{*}$ & $7.8 \pm 4.8$ \\
\hline No. of available embryos & $5.0 \pm 2.8$ & $5.7 \pm 3.0^{*}$ & $5.9 \pm 3.2$ \\
\hline Fertilization rate (\%) & 69 & $67.4^{*}$ & $65.1^{*}$ \\
\hline Cleavage rate (\%) & 97.8 & 97.7 & $97.3^{* *}$ \\
\hline No. of transferred embryos & $2.10 \pm 0.34$ & $2.12 \pm 0.34^{*}$ & $2.14 \pm 0.39$ \\
\hline No. of transferred top-quality embryos & $1.97 \pm 0.55$ & $2.00 \pm 0.53^{* *}$ & $2.02 \pm 0.56^{*}$ \\
\hline Implantation rate (\%) & 36.3 & $31.6^{*}$ & $26^{*}$ \\
\hline CPR (\%) & 50.4 & $45.5^{*}$ & $36.2^{*}$ \\
\hline
\end{tabular}

Note: Day 3 ET subgroups according progesterone cut-off levels: $<1 \mathrm{ng} / \mathrm{ml}, 1-1.49 \mathrm{ng} / \mathrm{ml}$, and $\geq 1.5 \mathrm{ng} / \mathrm{ml}$. $\mathrm{P}=$ progesterone

${ }^{a}$ All values are presented as the mean \pm SD or count (\%)

${ }^{\mathrm{b}}$ Differences between subgroups were determined using ANOVA followed by the LSD- $t$ test or the Kruskal-Wallis (KW) test and subsequent pairwise multiple comparisons for continuous variables and the chi-square test or Fisher's exact test for categorical variables

${ }^{*} p<0.01$ compared with the previous subgroup

${ }_{* *} p<0.05$ compared with the previous subgroup

may indicate that this subgroup had a better ovarian response. However, this subgroup presented significantly lower IRs (29.5\% VS. $46.2 \%, p=0.002)$ and CPRs $(31.3 \%$ VS. $41.4 \%, p<0.001)$ compared with the $<1.75 \mathrm{ng} / \mathrm{ml}$ subgroup with more transferred embryos. In addition, female age was significantly higher in the $\geq 1.75 \mathrm{ng} / \mathrm{ml}$ subgroup ( $31.5 \pm 5.2$ VS. $29.5 \pm 4.4 \mathrm{y}, p$ $=0.002)$.

\section{Discussion}

This study showed that PE on the day of hCG administration decreased CPRs in both cleavage- and blastocyststage ET cycles using gonadotropin and GnRH agonist for controlled ovarian stimulation. In the day $3 \mathrm{ET}$ cycles, a serum progesterone concentration of $1.0 \mathrm{ng} / \mathrm{ml}$ had a detrimental effect on CPRs. This detrimental effect worsened when the progesterone concentration reached $1.5 \mathrm{ng} / \mathrm{ml}$. However, in the day 5 blastocyst-stage ET cycles, the detrimental effect did not appear until the progesterone concentration reached $1.75 \mathrm{ng} / \mathrm{ml}$. The negative associations of PE with CPRs in both the day 3 and day 5 ET groups were the same after adjusting for confounders using multivariate analysis. Furthermore, the non-significant value of the test of the interaction between the developmental stage of the transferred embryos and PE with CPRs further confirmed that PE on the day of hCG administration was negatively associated with clinical pregnancy, regardless of the developmental stage of the transferred embryos.

Our results reaffirm the conclusions of previous retrospective studies that serum progesterone elevation on the day of hCG administration inversely impacts the pregnancy outcomes of patients undergoing IVF $[1,6,10,11]$. In our study of more than 10,000 day 3 ET patients, we found that the detrimental effect of PE began at a threshold level $1.0 \mathrm{ng} / \mathrm{ml}$ and worsened when the level reached $1.5 \mathrm{ng} / \mathrm{ml}$, which was similar to the findings of a recent meta-analysis [1] showing that progesterone levels (range: 0.8-1.1 $\mathrm{ng} / \mathrm{ml}$ ) have detrimental effects that worsen when the progesterone concentration reaches $1.2 \mathrm{ng} / \mathrm{ml}$. Additionally, our study provides support for the nonlinear relationship between the progesterone levels on the day of hCG administration and pregnancy outcomes in fresh IVF cycles $[1,6]$.

Clinicians have utilized different strategies for controlling PE with the aim of avoiding its possible detrimental effects in fresh IVF cycles. Such PE control strategies include employing a mild stimulation protocol to achieve 
Table 6 Comparison of demographic and clinical characteristics between subgroups of the day 5 ET group

\begin{tabular}{|c|c|c|c|}
\hline \multirow[t]{2}{*}{ Parameter $^{a}$} & \multicolumn{2}{|c|}{ Serum P levels $(\mathrm{ng} / \mathrm{ml})$, day $5 \mathrm{ET}$} & \multirow[t]{2}{*}{$P$-value } \\
\hline & $<1.75$ & $\geq 1.75$ & \\
\hline No. of fresh cycles & 1066 & 80 & \\
\hline Female age (years) & $29.5 \pm 4.4$ & $31.5 \pm 5.2$ & 0.002 \\
\hline BMI $\left(\mathrm{kg} / \mathrm{m}^{2}\right)$ & $22.60 \pm 3.31$ & $21.95 \pm 2.59$ & 0.036 \\
\hline Basal FSH (IU/L) & $6.61 \pm 1.57$ & $6.53 \pm 1.83$ & NS \\
\hline Total dose of Gn (IU) & $1760.0 \pm 635.5$ & $2114.1 \pm 680.7$ & $<0.001$ \\
\hline Serum E2 $(\mathrm{pg} / \mathrm{ml}), \mathrm{hCG}$ day & $7583.3 \pm 2595.8$ & $9200.6 \pm 3038.1$ & $<0.001$ \\
\hline Serum LH (IU/L), hCG day & $1.6 \pm 0.7$ & $1.5 \pm 0.7$ & NS \\
\hline Endometrial thickness (mm), hCG day & $12.2 \pm 2.3$ & $12.1 \pm 2.5$ & NS \\
\hline No. of oocytes retrieved & $17.9 \pm 5.0$ & $19.7 \pm 4.9$ & 0.003 \\
\hline No. of 2PN oocytes & $13.1 \pm 3.8$ & $14.4 \pm 4.3$ & 0.014 \\
\hline No. of 2PN cleavage embryos & $12.9 \pm 3.8$ & $14.2 \pm 4.3$ & 0.003 \\
\hline No. of available embryos & $9.7 \pm 3.8$ & $9.9 \pm 4.8$ & 0.031 \\
\hline Fertilization rate (\%) & 74.4 & 73.5 & NS \\
\hline Cleavage rate (\%) & 98.5 & 99.1 & NS \\
\hline No. of transferred embryos & $1.08 \pm 0.27$ & $1.19 \pm 0.39$ & 0.017 \\
\hline ET with top-quality blastocyst (\%) & 58.7 & 52.7 & NS \\
\hline Implantation rate (\%) & 46.2 & 29.5 & 0.002 \\
\hline CPR (\%) & 41.4 & 21.3 & $<0.001$ \\
\hline
\end{tabular}

Note: Day 5 ET subgroups according progesterone cut-off levels: $<1.75 \mathrm{ng} / \mathrm{ml}, \geq 1.75 \mathrm{ng} / \mathrm{ml}$; NS = not statistically significant

${ }^{a}$ All values are presented as the mean \pm SD or count $(\%)$

*Differences between subgroups were determined using Student's $t$-test or the Mann-Whitney $U$ test for continuous variables and the chi-square test or Fisher's exact test for categorical variables

lower estradiol levels [19] or an earlier hCG trigger in high responders to avoid PE in the late follicular phase [20]. Other strategies that have been used to increase the probability of pregnancy in cases of PE in fresh IVF cycles included canceling fresh ETs and replacing the fresh embryos with frozen-thawed embryos in natural cycles. However, a recent retrospective analysis revealed that the incidence of PE (serum progesterone $\geq 1.57 \mathrm{ng} /$ $\mathrm{ml}$ ) in frozen-thawed embryo-transferred natural cycles was similar to that in fresh stimulated cycles [29].

Replacing cleavage-stage embryos with blastocyst-stage embryos prior to transfer has also been advocated since a previous study found that PE on the day of hCG administration decreased pregnancy rates in day 3 single ET cycles but not in day 5 single blastocyst transfer cycles. It was assumed that the endometrium had already significantly recovered from the impairment caused by supra-physiological steroid concentrations on the fifth luteal day $[7,21]$. Although other studies have supported this hypothesis $[9,30]$, the reliability of this procedure still requires confirmation. In the present study, PE adversely affected CPRs when the progesterone level was $\geq 1.75 \mathrm{ng} / \mathrm{ml}$ in the day 5 blastocyst-stage ET group, a finding that is in agreement with previous suggestions that PE could impair IVF outcomes even with blastocyst transfers $[8,13,22]$. Furthermore, our interaction test did not reveal a link between the developmental stage of the transferred embryos and the effect of PE on clinical pregnancy [1].

In our study, we also used multivariate analysis to assess the detrimental effects of PE on CPRs [31] because parameters other than PE are closely related to IVF pregnancy outcomes [5, 32]. The results of this analysis showed that the number of top-quality transferred embryos had a positive effect on CPRs in both the day 3 and day 5 ET groups. Female age had a negative effect only in the day 5 ET group. In accordance with this result, female age is considered an independent factor related to clinical pregnancy because of age-related changes in the ovarian reserve, oocyte quality, embryo quality, and the uterine environment $[33,34]$. However, oocyte number, which has been demonstrated to be correlated with PE [28] and strongly related to the probability of pregnancy and live birth $[1,3,5,6]$, was not confirmed to be related to CPRs in our study.

In IVF cycles, the luteal-phase endometrium is altered by the supra-physiological steroid concentration induced by ovarian hyperstimulation [21]. When the progesterone level is $>1.5 \mathrm{ng} / \mathrm{ml}$ on the day of hCG administration, differences in gene expression in the endometrium occur after $36 \mathrm{~h}$ [35]. Our data also indicated that CPRs and implantation rates were obviously reduced when the 
progesterone level was $>1.5 \mathrm{ng} / \mathrm{ml}$ in the day $3 \mathrm{ET}$ group. A functional genomics analysis of the endometrium also confirmed that gene expression was altered in the endometrium as a result of PE on the day of hCG administration [16, 17]. In stimulated cycles, advanced endometrial maturation induced by PE may be related to the earlier closure of the implantation window and a reduction in pregnancy rates $[14,15]$. Taken together, these observations indicate that endometrial receptivity is impaired by elevated progesterone, which may explain the poor IVF pregnancy outcomes. However, oocyte quality may not be affected $[1,18]$, as our data indicate that the fertilization and cleavage rates were not significantly different in the day 5 ET subgroups.

Comparisons between the subgroups of the day 3 and day 5 ET groups revealed that PE was associated with increased gonadotropin dose [1], oocyte number and E2 levels $[5,8,11]$, which is in agreement with previous studies. These results may have occurred because each individual follicle contributes to the progesterone concentration in the circulation [36].

Interestingly, the cut-off levels for PE-induced impairment were different in the day 3 and day 5 ET groups in our study. Because the sample size of the day 3 ET group was sufficiently large (it contained more than $10,000 \mathrm{pa}-$ tients) and it included all patients regardless ovarian response $[5,6,31]$, the cut-off levels $(1.0$ and $1.5 \mathrm{ng} / \mathrm{ml})$ of the day 3 ET group may significantly represent the thresholds in the general population. However, the cutoff levels $(1.75 \mathrm{ng} / \mathrm{ml})$ of the day $5 \mathrm{ET}$ group may be limited because of its smaller sample size $(n=1146)$. Moreover, the day 5 blastocyst-stage ET group tended to include good ovarian responders with high serum steroid levels as a result of the criteria for blastocyst transfer in our study.

The same progesterone assay used in our study and the quality control of the assay in our individual laboratory ensured the consistency of our progesterone measurement and minimized any variability in our assay [37]. However, because the assays in different institutes vary [3], our thresholds may differ from those of other studies that used different assays. Overall, our findings have the following clinical implications: serum progesterone levels should be controlled during controlled ovarian stimulation to avoid the detrimental effects of PE, replacing cleavage-stage embryos with blastocysts before transfer is not effective for avoiding the detrimental effects of PE, and utilizing a multivariate approach to assess the effects of $\mathrm{PE}$ in a given population and identifying specific cutoffs for that population in clinical practice is important.

In conclusion, this study shows that PE on the day of hCG administration is associated with decreased CPRs in GnRH agonist IVF/ICSI cycles regardless of the developmental stage of ET (cleavage versus blastocyst stage).

\section{Abbreviations}

PE: Progesterone elevation; hCG: human Chorionic gonadotropin; IVF: In vitro fertilization; ICSI: Intracytoplasmic sperm injection; GnRH: Gonadotropinreleasing hormone; CPR: Clinical pregnancy rate; IR: Implantation rate; ET: Embryo transfer; FSH: Follicle-stimulating hormone; BMI: Body mass index; 2PN: two Pronuclear; OR: Odds ratio; Cl: Confidence interval; COS: Controlled ovarian stimulation; PCOS: Polycystic ovary syndrome; SD: Standard deviation.

\section{Competing interests}

The authors declare that they have no competing interests.

\section{Authors' contributions}

Ying-pu Sun, Yan Huang and En-yin Wang contributed to the study design, analysis and interpretation of data and manuscript preparation; Yan Huang, Qing-yun Du Xiao-yi Guo, Yi-ping Yu and Yu-jing Xiong handled patient recruitment, data collection and statistical work. All authors read and approved the final manuscript.

\section{Authors' information}

Yan Huang and En-yin Wang are joint first authors.

\section{Acknowledgements}

This study was supported by the National Natural Science Foundation of China (No. U1304314). The work was also supported by grants from the Henan Province Education Department (No. 13A320461) and the Youth Foundation, The First Hospital of Zhengzhou University (2014, En-yin Wang). The language corrections in this study were made with the help of American Journal Experts (AJE).

Received: 13 May 2015 Accepted: 13 July 2015

Published online: 04 August 2015

\section{References}

1. Venetis CA, Kolibianakis EM, Bosdou JK, Tarlatzis BC. Progesterone elevation and probability of pregnancy after IVF: a systematic review and metaanalysis of over 60000 cycles. Hum Reprod Update. 2013;19(5):433-57. doi:10.1093/humupd/dmt014.

2. Martinez F, Coroleu B, Clua E, Tur R, Buxaderas R, Parera N, et al. Serum progesterone concentrations on the day of HCG administration cannot predict pregnancy in assisted reproduction cycles. Reprod Biomed Online. 2004:8(2):183-90.

3. Venetis CA, Kolibianakis EM, Papanikolaou E, Bontis J, Devroey P, Tarlatzis BC. Is progesterone elevation on the day of human chorionic gonadotrophin administration associated with the probability of pregnancy in in vitro fertilization? A systematic review and meta-analysis. Hum Reprod Update. 2007;13(4):343-55. doi:10.1093/humupd/dmm007.

4. Seow KM, Lin YH, Huang LW, Hsieh BC, Huang SC, Chen CY, et al. Subtle progesterone rise in the single-dose gonadotropin-releasing hormone antagonist (cetrorelix) stimulation protocol in patients undergoing in vitro fertilization or intracytoplasmic sperm injection cycles. Gynecol Endocrinol. 2007;23(6):338-42. doi:10.1080/09513590701403629.

5. Xu B, Li Z, Zhang H, Jin L, Li Y, Ai J, et al. Serum progesterone level effects on the outcome of in vitro fertilization in patients with different ovarian response: an analysis of more than 10,000 cycles. Fertility and sterility. 2012;97(6):1321-7 e1-4. doi:10.1016/j.fertnstert.2012.03.014.

6. Bosch E, Labarta E, Crespo J, Simon C, Remohi J, Jenkins J, et al. Circulating progesterone levels and ongoing pregnancy rates in controlled ovarian stimulation cycles for in vitro fertilization: analysis of over 4000 cycles. Hum Reprod. 2010;25(8):2092-100. doi:10.1093/humrep/deq125.

7. Papanikolaou EG, Kolibianakis EM, Pozzobon C, Tank P, Tournaye H,

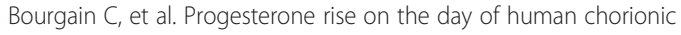
gonadotropin administration impairs pregnancy outcome in day 3 singleembryo transfer, while has no effect on day 5 single blastocyst transfer. Fertil Steril. 2009;91(3):949-52. doi:10.1016/j.fertnstert.2006.12.064.

8. Ochsenkuhn R, Arzberger A, von Schonfeldt V, Gallwas J, Rogenhofer N, Crispin A, et al. Subtle progesterone rise on the day of human chorionic gonadotropin administration is associated with lower live birth rates in women undergoing assisted reproductive technology: a retrospective study with 2,555 fresh embryo transfers. Fertil Steril. 2012;98(2):347-54. doi:10.1016/j.fertnstert.2012.04.041. 
9. Elgindy EA. Progesterone level and progesterone/estradiol ratio on the day of hCG administration: detrimental cutoff levels and new treatment strategy. Fertil Steril. 2011;95(5):1639-44. doi:10.1016/j.fertnstert.2010.12.065.

10. Fanchin R, de Ziegler D, Taieb J, Hazout A, Frydman R. Premature elevation of plasma progesterone alters pregnancy rates of in vitro fertilization and embryo transfer. Fertil Steril. 1993;59(5):1090-4.

11. Kilicdag EB, Haydardedeoglu B, Cok T, Hacivelioglu SO, Bagis T. Premature progesterone elevation impairs implantation and live birth rates in $\mathrm{GnRH}$ agonist IVF/ICSI cycles. Arch Gynecol Obstet. 2010;281(4):747-52. doi:10.1007/s00404-009-1248-0.

12. Urman B, Alatas C, Aksoy S, Mercan R, Isiklar A, Balaban B. Elevated serum progesterone level on the day of human chorionic gonadotropin administration does not adversely affect implantation rates after intracytoplasmic sperm injection and embryo transfer. Fertil Steril. 1999;72(6):975-9.

13. Fanchin R, Hourvitz A, Olivennes F, Taieb J, Hazout A, Frydman R. Premature progesterone elevation spares blastulation but not pregnancy rates in in vitro fertilization with coculture. Fertil Steril. 1997;68(4):648-52.

14. Kolibianakis EM, Bourgain C, Papanikolaou EG, Camus M, Tournaye H, Van Steirteghem AC, et al. Prolongation of follicular phase by delaying hCG administration results in a higher incidence of endometrial advancement on the day of oocyte retrieval in GnRH antagonist cycles. Hum Reprod. 2005;20(9):2453-6. doi:10.1093/humrep/dei069.

15. Develioglu OH, Hsiu JG, Nikas G, Toner JP, Oehninger S, Jones Jr HW. Endometrial estrogen and progesterone receptor and pinopode expression in stimulated cycles of oocyte donors. Fertil Steril. 1999;71(6):1040-7.

16. Van Vaerenbergh I, Van Lommel L, Ghislain V, In't Veld P, Schuit F, Fatemi $H M$, et al. In GnRH antagonist/rec-FSH stimulated cycles, advanced endometrial maturation on the day of oocyte retrieval correlates with altered gene expression. Hum Reprod. 2009;24(5):1085-91. doi:10.1093/ humrep/den501.

17. Labarta E, Martinez-Conejero JA, Alama P, Horcajadas JA, Pellicer A, Simon C, et al. Endometrial receptivity is affected in women with high circulating progesterone levels at the end of the follicular phase: a functional genomics analysis. Hum Reprod. 2011;26(7):1813-25. doi:10.1093/humrep/ der126.

18. Lahoud R, Kwik M, Ryan J, Al-Jefout M, Foley J, Illingworth P. Elevated progesterone in GnRH agonist down regulated in vitro fertilisation (IVFICSI) cycles reduces live birth rates but not embryo quality. Arch Gynecol Obstet. 2012;285(2):535-40. doi:10.1007/s00404-011-2045-0.

19. Kolibianakis EM, Albano C, Camus M, Tournaye H, Van Steirteghem AC, Devroey P. Prolongation of the follicular phase in in vitro fertilization results in a lower ongoing pregnancy rate in cycles stimulated with recombinant follicle-stimulating hormone and gonadotropin-releasing hormone antagonists. Fertil Steril. 2004;82(1):102-7. doi:10.1016/j.fertnstert.2004.01.027.

20. Al-Azemi M, Kyrou D, Kolibianakis EM, Humaidan P, Van Vaerenbergh I, Devroey $\mathrm{P}$, et al. Elevated progesterone during ovarian stimulation for IVF. Reprod Biomed Online. 2012;24(4):381-8. doi:10.1016/j.rbmo.2012.01.010.

21. Bourgain C, Devroey P. The endometrium in stimulated cycles for IVF. Hum Reprod Update. 2003;9(6):515-22.

22. Corti L, Papaleo E, Pagliardini L, Rabellotti E, Molgora M, La Marca A, et al. Fresh blastocyst transfer as a clinical approach to overcome the detrimental effect of progesterone elevation at hCG triggering: a strategy in the context of the Italian law. Eur J Obstet Gynecol Reprod Biol. 2013;171(1):73-7. doi:10.1016/j.jogrb.2013.08.017.

23. Garcia-Velasco JA, Bermejo A, Ruiz F, Martinez-Salazar J, Requena A, Pellicer A. Cycle scheduling with oral contraceptive pills in the GnRH antagonist protocol vs the long protocol: a randomized, controlled trial. Fertil Steril. 2011;96(3):590-3. doi:10.1016/j.fertnstert.2011.06.022.

24. Zhang HJ, Song XR, Lu R, Xue FX. Modified super-long down-regulation protocol improves fertilization and pregnancy in patients with poor ovarian responses. Chin Med J (Engl). 2012;125(16):2837-40.

25. Balaban B, Urman B, Isiklar A, Alatas C, Aksoy S, Mercan R, et al. The effect of pronuclear morphology on embryo quality parameters and blastocyst transfer outcome. Hum Reprod. 2001;16(11):2357-61.

26. Gardner DK, Lane M, Schoolcraft WB. Culture and transfer of viable blastocysts: a feasible proposition for human IVF. Hum Reprod. 2000;15 Suppl 6:9-23.

27. Tsai YR, Huang FJ, Lin PY, Kung FT, Lin YJ, Lin YC, et al. Progesterone elevation on the day of human chorionic gonadotropin administration is not the only factor determining outcomes of in vitro fertilization. Fertil Steril. 2015;103(1):106-11. doi:10.1016/j.fertnstert.2014.10.019.
28. Lee VC, Li RH, Chai J, Yeung TW, Yeung WS, Ho PC, et al. Effect of preovulatory progesterone elevation and duration of progesterone elevation on the pregnancy rate of frozen-thawed embryo transfer in natural cycles. Fertil Steril. 2014;101(5):1288-93. doi:10.1016/ j.fertnstert.2014.01.040.

29. Li RR, Dong YZ, Guo YH, Sun YP, Su YC, Chen F. Comparative study of pregnancy outcomes between day 3 embryo transfer and day 5 blastocyst transfer in patients with progesterone elevation. J Int Med Res. 2013;41(4):1318-25. doi:10.1177/0300060513489480.

30. Venetis CA, Kolibianakis EM, Bosdou JK, Lainas GT, Sfontouris IA, Tarlatzis BC, et al. Estimating the net effect of progesterone elevation on the day of hCG on live birth rates after IVF: a cohort analysis of 3296 IVF cycles. Hum Reprod. 2015;30(3):684-91. doi:10.1093/humrep/deu362.

31. Kolibianakis EM, Venetis CA, Bontis J, Tarlatzis BC. Significantly lower pregnancy rates in the presence of progesterone elevation in patients treated with GnRH antagonists and gonadotrophins: a systematic review and meta-analysis. Curr Pharm Biotechnol. 2012;13(3):464-70.

32. van Rooij IA, Bancsi LF, Broekmans FJ, Looman CW, Habbema JD, te Velde ER. Women older than 40 years of age and those with elevated folliclestimulating hormone levels differ in poor response rate and embryo quality in in vitro fertilization. Fertil Steril. 2003;79(3):482-8.

33. Baird DT, Collins J, Egozcue J, Evers LH, Gianaroli L, Leridon H, et al. Fertility and ageing. Hum Reprod Update. 2005;11(3):261-76. doi:10.1093/humupd/ dmi006.

34. Sunkara SK, Rittenberg V, Raine-Fenning N, Bhattacharya S, Zamora J, Coomarasamy A. Association between the number of eggs and live birth in IVF treatment: an analysis of 400135 treatment cycles. Hum Reprod. 2011;26(7):1768-74. doi:10.1093/humrep/der106.

35. Van Vaerenbergh I, Fatemi HM, Blockeel C, Van Lommel L, In't Veld P, Schuit $F$, et al. Progesterone rise on HCG day in GnRH antagonist/rFSH stimulated cycles affects endometrial gene expression. Reprod Biomed Online. 2011;22(3):263-71. doi:10.1016/j.rbmo.2010.11.002.

36. Andersen AN, Witjes $\mathrm{H}$, Gordon K, Mannaerts B. Predictive factors of ovarian response and clinical outcome after IVF/ICSI following a rFSH/GnRH antagonist protocol with or without oral contraceptive pre-treatment. Hum Reprod. 2011;26(12):3413-23. doi:10.1093/humrep/der318.

37. Patton PE, Lim JY, Hickok LR, Kettel LM, Larson JM, Pau KY. Precision of progesterone measurements with the use of automated immunoassay analyzers and the impact on clinical decisions for in vitro fertilization. Fertil Steril. 2014;101(6):1629-36. doi:10.1016/j.fertnstert.2014.02.037.

\section{Submit your next manuscript to BioMed Central and take full advantage of:}

- Convenient online submission

- Thorough peer review

- No space constraints or color figure charges

- Immediate publication on acceptance

- Inclusion in PubMed, CAS, Scopus and Google Scholar

- Research which is freely available for redistribution

Submit your manuscript at www.biomedcentral.com/submit
C BioMed Central 